\title{
PINTO, C. M., CARVALHO, E. P., \& COLAÇO, S. (Orgs.). (2012). Projetos de letramentos: Debates e aplicações. São Vicente do Sul: IFFarroupilha
}

A obra Projetos de letramentos: Debates e aplicações surgiu de uma proposta de trabalho integrado de professores do Instituto Federal Farroupilha - Campus São Vicente do Sul com professores de educação básica de escolas da região, pela necessidade de se estabelecer um diálogo entre professores que trabalham com a área de Linguagens e suas Tecnologias e os materiais didáticos disponíveis no mercado editorial. O livro está dividido em três partes: a primeira apresenta a seção Debates, em que são apresentados textos teóricos relacionados a letramentos, na visão dos Novos Estudos do Letramento (New Literacy Studies - Heath, 1983; Street, 1995, 2012; Gee, 1999, 2009; Lankshear \& Knobel, 1998; Cope \& Kalantzis, 2000; Durrant \& Green, 2001; Dionísio, 2007), que argumentam a favor do caráter sociocultural e situado das práticas de letramento; a segunda parte Aplicações - é composta por textos que descrevem projetos de letramento; e a seção final - Atividades de leitura e escrita: projetos de letramento apresenta alguns exemplos de atividades elaboradas por professores de linguagens da educação básica durante um curso sobre elaboração de materiais didáticos para o ensino da leitura oferecido pelo IFFarroupilha Campus São Vicente do Sul, via curso de formação continuada de professores, no ano de 2011.

A seção Debates inicia com o texto de Raquel Bevilaqua e Silvania Faccin Colaço, com o título "Letramentos na contemporaneidade: perspectivas teóricas". Nesse texto, as autoras abordam a pós-modernidade e seus reflexos na educação, discutindo desde questões iluministas até as pós-modernas e suas relações com a escola, com sustentação em Harvey (2010) e Bauman (2007). Na sequência, apresentam reflexões e questionamentos sobre os instrumentos Prova Brasil e SAEB (Sistema Nacional de Avaliação da Educação Básica), que medem os processos e resultados do letramento escolar no Brasil e as consequências disso para a educação, como a crítica questão das práticas de letramentos nas escolas brasileiras, além do PISA (Programa Internacional de Avaliação de Estudantes), que é um instrumento internacional. As autoras fazem uma 
retrospectiva do uso do termo 'letramentos' no Brasil, que, inicialmente, foi confundido com alfabetização. É apresentada a ideia inicial de Mary Kato (1990), que traz a concepção de sujeito letrado para responder às demandas sociais, diferenciando, assim, da simples habilidade de leitura e escrita ou alfabetização e assumindo uma concepção de letramento como linguagem em uso em práticas sociais (Kleiman, 1995; Soares, 1998). É destacada a necessidade de novas perspectivas para os letramentos na contemporaneidade, discutindo os desafios da relação entre as práticas de letramento escolar e a sociedade da pós-modernidade.

No texto "Letramentos e leitura nas perspectivas autônoma e ideológica", de Silvania Faccin Colaço, analisam-se os letramentos com base nas concepções de Street (1995) quanto aos modelos de letramento autônomo (as capacidades individuais) e ideológico (as práticas sociais envolvidas na leitura e escrita). Num primeiro momento, são discutidas as estratégias de leitura como atividades necessárias à compreensão leitora, em que as capacidades do leitor interagem com as informações do texto, numa concepção de leitura interativa (Kleiman, 1989; Leffa, 1996). Posteriormente, a leitura é discutida numa visão mais alargada, a das práticas sociais, possíveis de integrar a concepção ideológica (Street, 1995; Gee, 1999), que considera os usos da leitura e escrita como construções socioculturais. No entendimento de letramentos múltiplos, ou seja, práticas sociais e situadas de usos de textos multimodais, são apresentadas, a seguir, as práticas escolares e não-escolares de letramento, enfatizando a importância de ambas para a aprendizagem e a construção da criticidade do sujeito. O texto coloca o professor como um agente de letramentos, que deve promover situações significativas de aprendizagem para que seus alunos aprendam a usar textos e agir nas diversas situações sociocomunicativas de que participam em sociedade.

Em "Reflexões sobre leitura em língua estrangeira", de Graciele Turchetti de Oliveira Denardi, Lucas Martins Flores e Cândida Martins Pinto, encontram-se discussões sobre as teorias de linguagem abordadas nos documentos oficiais, nomeadamente os Parâmetros Curriculares Nacionais do Ensino Fundamental e Médio (PCNs) e as Orientações Curriculares Nacionais para o Ensino Médio (OCNs), sobre o ensino de língua estrangeira no Brasil. Os PCNs enfatizam que é preciso pensar no processo de ensino- 
aprendizagem das línguas estrangeiras em termos de competências abrangentes e não estáticas, uma vez que uma língua é o veículo, por excelência, de comunicação do povo. A leitura é destacada pelo documento como uma dessas competências, numa visão sociointeracional da aprendizagem (Borges, 2003). As OCNs também enfatizam a leitura, numa concepção crítica, voltada à formação da cidadania. À luz de autores da área (Leffa, 1996; Moita Lopes, 1996; Kleiman, 2007; Motta-Roth, 2007), o texto faz abordagens que consideram o leitor em contexto, vindo ao encontro do que se designa, hoje, estudos socioculturais dos letramentos. O texto encerra-se com uma proposta de atividade para o ensino da leitura, baseada nas práticas sociais e na leitura crítica, num processo de ação-reflexão-ação sobre o mundo.

O texto "Mídia e Educação: o uso das novas tecnologias em sala de aula", de autoria de Sabrine Denardi de Menezes da Silva, trata da tecnologia como aliada no processo de ensino-aprendizagem, mostrando algumas possibilidades de aproximar a sala de aula aos letramentos de que os alunos precisam se apropriar fora dela. Neste sentido, apresenta um panorama das relações estabelecidas pelas novas mídias na sociedade, a que se tem chamado de TIC (Tecnologias de Informação e Comunicação) e sua influência no contexto educacional, o que implica novas posturas e metodologias na atuação dos professores. Mais especificamente, são abordadas questões relativas ao uso da tecnologia nas aulas de Língua Portuguesa, com alternativas para a execução de uma possibilidade, explorando os multiletramentos dos sujeitos. A autora sugere que a escola pode ser um importante meio de inclusão digital para os cidadãos, a partir de aulas que possibilitem a interação, a autonomia e a motivação dos alunos.

Trazendo discussões sobre questões legais e a realidade educacional, o texto "Para problematizar metanarrativas: lei 11.645/08 e identidades indígenas", de autoria de Letícia Mossate Jobin, Daniela Farias Garcia de Borba e Luís Fernando Lazzarin, aborda a cultura indígena em sala de aula, segundo a lei específica que determina a inclusão dessa temática nos currículos escolares. O texto descreve uma proposta de estudo que estabelece um diálogo acerca da referida lei e das possibilidades de problematizar e questionar metanarrativas que produzem uma identidade idealizada de índio. A proposta recai numa concepção de culturas não-fixas, 
em constante produção de identidades indígenas múltiplas e híbridas, com análise de diversos artefatos culturais (mídia, artes visuais, músicas, imagens, livros didáticos), como dispositivos pedagógicos, a fim de redefinir conceitos sobre cultura e identidade, de acordo com a perspectiva teórica dos Estudos Culturais. Essa intervenção explora os multiletramentos do sujeito para analisar o contexto atual do índio e contestar a imagem de uma identidade única e fixa, a partir de leitura crítica de textos multimodais. O texto encerra com a análise de depoimentos de professores de educação básica e de estudantes de ensino médio frente à questão cultural do indígena, pois demonstram que quem tem o poder de narrar pode determinar que posição o outro ocupa. Além disso, os depoimentos apontam para o fato de que as pessoas estão atreladas a quadros de referências que instituem lugares para 'nós' e 'os outros', bem como o estranhamento, desconforto, instabilidade e resistência causados pela dissolução desses lugares.

"Os processos de letramento em Língua Portuguesa: um estudo dos sentidos no PROEJA", da autoria de Evanir Piccolo Carvalho, é um texto que aborda, a partir de olhares e discursos dos sujeitos de PROEJA (Programa de Educação de Jovens e Adultos), aspectos relevantes para o grupo sobre os processos de construção do conhecimento, em especial dos letramentos em Língua Portuguesa. O texto apresenta uma fundamentação bakhtiniana de linguagem ao enfatizar a perspectiva dialógica e sociocultural dos discursos sobre os processos de letramento, em narrativas de estudantes do PROEJA. A autora faz referência aos sentidos da leitura e da escrita para esses estudantes e leva em consideração as vivências dos sujeitos dentro e fora da escola. Apresenta ainda as dificuldades, de ordem escolar e de ordem pessoal, que os estudantes apresentam pelo caminho, e a mediação que surge como um elemento mobilizador de aprendizagem. O texto mostra como as narrativas revelam as práticas de letramento, evidenciando também sentidos que ajudam a compreender o processo de aprendizagem da leitura e escrita.

A segunda parte do livro - Aplicações - inicia com o texto "Curso técnico integrado e as práticas de letramento: experiência que gera aprendizado", de Cândida Martins Pinto. A autora descreve e comenta um projeto integrado realizado com uma turma de ensino médio do Curso Técnico em Agropecuária. Trata-se de um projeto que visou o trabalho de leitura e 
escrita de gêneros discursivos pertencente aos letramentos da esfera profissional em que a prática social direcionou a escolha dos textos trabalhados em sala de aula. $O$ artigo também discorre sobre as concepções de letramento que embasaram teoricamente o projeto, bem como analisa como os estudantes conseguiram assumir papéis ativos ao se inserirem no ambiente profissional que irão atuar. Por fim, a autora conclui que a experiência pedagógica demonstrou uma aprendizagem significativa, já que os estudantes adquiriram uma visão mais crítica e transformadora em relação à profissão escolhida.

O texto "O modelo interativo na leitura instrumental em língua estrangeira", de Carla Callegaro Corrêa Kader, discute como a estratégia de leitura interativa está inserida em uma seção de um Caderno Didático de Língua Inglesa Instrumental, criado por professoras de um colégio federal, com ênfase no uso da linguagem em um contexto específico, o que caracteriza uma prática situada de letramento. O texto apresenta abordagens relativas à leitura como processo interativo de construção de sentidos, indo além da simples decodificação. Ao abordar a leitura instrumental em língua estrangeira, explica o surgimento e evolução do termo 'instrumental', numa concepção em que prevalece o uso e a função dos textos na vida do sujeito, caracterizando a concepção sociocultural de práticas de letramento. A proposta de leitura instrumental com alunos de um curso de ensino médio de Agropecuária, na modalidade de ensino integrado, tem base em atividades de pré-leitura, leitura e pós-leitura, sendo que a autora defende a presença da prática social de linguagem, com o uso de textos advindos de contextos sociais diversos da realidade dos alunos.

"Práticas de letramento no PROEJA: buscando no passado uma identidade cidadã", texto de autoria de Silvania Faccin Colaço, contribui com um exemplo de projeto de letramento na sala de aula, a partir de diversos gêneros discursivos que contam a história de vida dos sujeitos. A prática ocorre com uma turma de alunos do curso técnico em Informática, na modalidade do Programa de Educação de Jovens e Adultos (PROEJA). O texto aborda a teoria dos letramentos na visão dos Novos Estudos do Letramento e a teoria bakhtiniana dos Gêneros Discursivos, que considera a linguagem como um processo de interação social (Bakhtin, 2000). O projeto de letramento centra-se no trabalho colaborativo, de acordo com uma 
Pedagogia de Multiletramentos, que prevê a prática situada, a instrução explícita, o enquadramento crítico e a prática transformadora (The New London Group, 1996). A proposta apresenta uma prática de letramento em que os textos são escritos e reescritos em sala de aula: fotografias, cartas, documentos, entrevistas, receitas, powerpoint, resumo e comunicação oral. A autora conclui que os resultados foram significativos para a inclusão dos alunos na turma, com a valorização do passado, a conscientização em relação ao presente e a projeção para o futuro.

"O jornal na sala de aula: projeto de letramento para o ensino da leitura e escrita", de Cândida Martins Pinto, descreve como foi desenvolvido um projeto de produção de um jornal e, posteriormente, sua divulgação num evento organizado por alunos do Curso Técnico em Secretariado, em que foram empregados os conhecimentos integrados de três disciplinas do curso: Informática, Técnicas e Práticas em Secretariado e Língua Portuguesa. A autora mostra como o jornal teve um duplo papel pedagógico, já que deu voz e autoria aos alunos, quando da produção de textos que seriam lidos pela comunidade escolar e não apenas pela professora; e como instrumento pedagógico que possibilitou a aprendizagem de gêneros dentro de um contexto de prática socialmente situada. Além disso, destaca que trabalhar com os textos, e não sobre os textos, permite inserir os estudantes em contextos reais, auxiliando, assim, no desenvolvimento crítico a partir da socialização e compreensão de práticas profissionais que serão a posteriori vivenciadas.

Em "Análise das atividades didáticas com vistas à identificação de instâncias de letramento científico", Janete Teresinha Arnt defende que a notícia de popularização da ciência é um gênero adequado para iniciar o processo de transição entre o estudo da linguagem do dia a dia e o estudo da linguagem científica, nas aulas de Língua Inglesa. $O$ artigo possui dois grandes objetivos: o primeiro deles propõe investigar em que medida o gênero notícia de popularização da ciência está sendo utilizado para iniciar o letramento científico dos alunos; o segundo, busca reelaborar atividades didáticas, a fim de promover o letramento científico. Para tal, é apresentada uma linha evolutiva das visões de letramento, com a opção pela que considera letramentos como práticas sociais de leitura e escrita. A proposta é apresentada a partir da análise de quatro livros de Inglês Instrumental, com 
atividades de pré-leitura, leitura e pós-leitura, com a exploração de notícias de popularização da ciência, a fim da promoção de letramentos científicos.

A terceira e última parte do livro apresenta o Caderno de Atividades, com o capítulo intitulado "Atividades de leitura e escrita: projetos de letramento", que se constitui de propostas elaboradas por professores de educação básica durante sua participação no curso sobre elaboração de material didático, no Instituto Federal Farroupilha - Campus São Vicente do Sul, para aulas de língua materna e de língua estrangeira. É feita uma contextualização teórica sobre gêneros discursivos e letramentos, tendo em vista que as atividades foram criadas na concepção de que os alunos apropriam-se de textos a fim de se inserirem nas práticas letradas da sociedade, de acordo com os papéis sociais que assumem. São apresentadas nove propostas didáticas de ensino da leitura e escrita para as disciplinas de Língua Portuguesa e Língua Inglesa. A intenção de mostrar essas atividades é de apresentar possibilidades de produção de material didático, a fim de estimular cada professor a criar seus projetos de letramento, de acordo com seu contexto específico e situado de ensino.

Com essa obra, os autores se propõem a promover reflexões sobre práticas de leitura e escrita numa perspectiva sociocultural, que possam vir a auxiliar professores da educação básica na elaboração de material didático.

\section{Referências}

Bakhtin, M. (2000). Os gêneros do discurso. In M. Bakhtin, A estética da criação verbal ( $3^{\mathrm{a}}$ ed.) (pp. 277-326). São Paulo: Martins Fontes.

Bauman, Z. (2007). Vida líquida. Rio de Janeiro: Zahar.

Borges, E. F. V. (2003). Discernimento do esteio teórico nos PCN de Língua Estrangeira - Ensino Fundamental (Dissertação de Mestrado). Universidade Estadual de Campinas - Instituto de Estudos da Linguagem, São Paulo.

Cope, B., \& Kalantzis, M. (Eds.). (2000). Multiliteracies: Literacy learning and the design of social futures. London: Routledge.

Dionísio, M. L. (2007). Educação e os estudos atuais sobre letramento - Entrevista concedida a Adriana Fisher e Nilcéa Lemos Pelandré. Perspectiva, 25(1), 209224.

Durrant, C., \& Green, B. (2001). Literacy and the new technologies in school education: Meeting the L(IT)eracy Challenge? In H. Fehring \& P. Green (Eds.), Critical literacy. Australia: Internacional Reading Association. 
Gee, J. P. (1999). Social linguistics and literacies: Ideology in discourses ( $2^{\mathrm{a}}$ ed.). London/Philadelphia: The Farmer Press.

Gee, J. P. (2009) The New Literacy Studies and the 'social turn'. Retirado de http://www.eric.ed.gov/PDFS/ED442118.pdf

Harvey, D. (2010). Condição pós-moderna ( $2^{\mathrm{a}}$ ed.). São Paulo: Loyola.

Heath, S. B. (1983). Ways with words: Language, life, and work in communities and classrooms. Cambridge: Cambridge University Press.

Kato, M. (1990). No mundo da escrita: Uma perspectiva psicolinguística. São Paulo: Ática.

Kleiman, A. (1989). Texto e leitor: Aspectos cognitivos da leitura. Campinas: Pontes.

Kleiman, A. (2007). Letramento e suas implicações para o ensino de língua materna. Signo, 32(52), 1-25.

Kleiman, A. (Org.). (1995). Os significados do letramento: Uma nova perspectiva sobre a prática social da escrita. Campinas, SP: Mercado de Letras.

Lankshear, C., \& Knobel, M. (1998). Critical literacy and new technologies. Retirado de http://everydayliteracies.net/files/critlitnewtechs.html

Leffa, V. J. (1996). Aspectos da leitura. Porto Alegre: Sagra.

Moita Lopes, L. P. (1996). Oficina de lingüística aplicada. Campinas, SP: Mercado das Letras.

Motta-Roth, D. (2007). A construção de uma abordagem de ensino de leitura em inglês no processo de formação do aluno de letras. Trabalho apresentado no Simpósio EFL Reading do $1^{\circ}$ Congresso Internacional da ABRAPUL, Belo Horizonte, MG: Universidade Federal de Minas Gerais/Associação Brasileira de Professores Universitários de Inglês e Literatura.

Soares, M. (1998). Letramento: Um tema em três gêneros. Belo Horizonte: Autêntica.

Street, B. (1995). Social literacies. Critical approaches to literacy in development. In Ethnography and education. Harow: Pearson.

Street, B. (2012). Literacy and multimodality. Retirado de http://arquivos.lingtec.org/stis/ STIS-LectureLitandMMMarch2012.pdf

The New London Group (1996). A pedagogy of multiliteracies: Designing social futures. Harvard Educational Review, 66(1), 60-92.

Silvania Faccin Colaço, bolsista CAPES N ${ }^{\circ}$ 19125-12-7

Cândida Martins Pinto, bolsista CAPES Nº 19124-12-0

Universidade Católica de Pelotas 